\title{
Effectiveness of a physical activity intervention program
}

\section{using peer support among sedentary women in}

\section{Thiruvananthapuram City, India: results of a non-randomized}

\section{quasi experimental study [version 1; peer review: 3 approved]}

\section{Elezebeth Mathews (D)1, Odile Sauzet (D)2, Kavumpurathu Raman Thankappan (iD)1}

${ }^{1}$ Department of Public Health and Community Medicine, Central University of Kerala, Kasaragod, Kerala, 671315, India
2Zentrum für Statistik, Universität Bielefeld, Bielefeld, Germany

V1 First published: $20 \mathrm{Apr} 2021,6: 87$

https://doi.org/10.12688/wellcomeopenres.16618.1

Latest published: $20 \mathrm{Apr} 2021, \mathbf{6 : 8 7}$

https://doi.org/10.12688/wellcomeopenres.16618.1

\section{Abstract}

Background: Interventions to promote physical activity are very limited in India. The objective of this study was to assess the effectiveness and sustainability of a peer support based physical activity (PA) intervention targeting sedentary women in Thiruvananthapuram City, India.

Methods: We used a non-randomized quasi-experimental study design with a comparison group. Using the Global Physical Activity Questionnaire (GPAQ) classifications, 401 sedentary women aged 1864 years were selected by multistage cluster sampling and enrolled into the intervention $(n=200)$ and control $(n=201)$ arms. For the intervention arm, a culturally relevant intervention was delivered to the community stakeholders, participants and peer leaders at three subsequent intensities: intense (three months), less intense (three months) and no intervention (six months). The intervention consisted of a non-communicable disease (NCD) risk assessment, educational workshop, group counselling sessions, goal setting, handbook and peer support. The control participants received printed information on NCDs and their risk factors. PA assessments and anthropometric measurements were made at baseline, $4^{\text {th }}, 7^{\text {th }}$ and $13^{\text {th }}$ months. Mixed model analysis was done to assess the difference in PA levels between groups at various time points.

Results: The proportion of women who were physically active $(\geq 600$ MET minutes per week) was significantly higher in the intervention arm compared to the control arm at $4^{\text {th }}(58.5 \%$ vs $10 \%, p=0.001), 7^{\text {th }}$ $(48.5 \%$ vs $6 \%, p=0.001))$ and $13^{\text {th }}$ month $(29.6 \%$ vs $0.6 \%, p=0.001)$, respectively. Improvements from baseline PA expended by the intervention arm compared to the control arm in MET-min / week were 990,575 , and 466 at $4^{\text {th }}, 7^{\text {th }}$ and $13^{\text {th }}$ months, respectively. Conclusions: A PA intervention using peer support was found to be

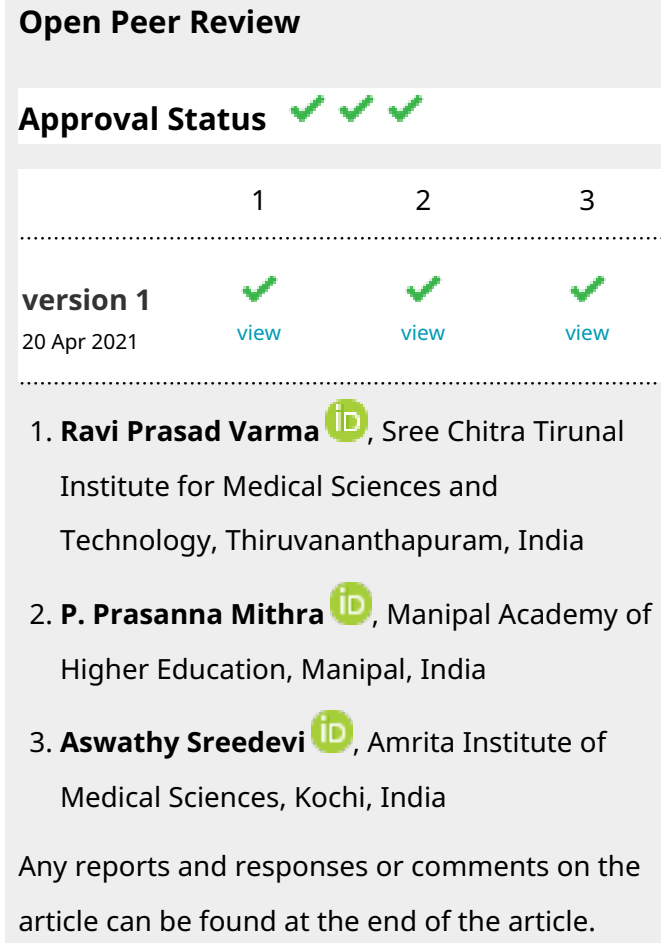

1. Ravi Prasad Varma ID Sree Chitra Tirunal Institute for Medical Sciences and Technology, Thiruvananthapuram, India

2. P. Prasanna Mithra (D), Manipal Academy of Higher Education, Manipal, India

3. Aswathy Sreedevi (iD), Amrita Institute of Medical Sciences, Kochi, India Any reports and responses or comments on the article can be found at the end of the article. 
effective among women in India. Improvements in PA in the intervention arm decreased over time particularly after the nointervention phase indicating the need for integrating it with community organizations.

\section{Keywords}

Physical activity, women, peer support, India, intervention, Kerala, non-randomized quasi-experimental study, community based

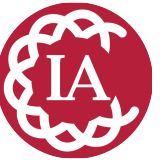

This article is included in the Wellcome

Trust/DBT India Alliance gateway.

Corresponding author: Elezebeth Mathews (dr.elezebethmathews@cukerala.ac.in)

Author roles: Mathews E: Conceptualization, Data Curation, Formal Analysis, Funding Acquisition, Investigation, Methodology, Project Administration, Resources, Visualization, Writing - Original Draft Preparation, Writing - Review \& Editing; Sauzet O: Formal Analysis, Validation, Visualization, Writing - Review \& Editing; Thankappan KR: Conceptualization, Project Administration, Supervision, Validation, Visualization, Writing - Review \& Editing

Competing interests: No competing interests were disclosed.

Grant information: EM is funded by the DBT/India Alliance Early career fellowship [IA/CPHE/17/1/50334]. This work has also been supported by the Asian Collaboration for Excellence in Non-Communicable Disease Research (ASCEND) and Global Peers for Progress, an Eli Lily Foundation.

The funders had no role in study design, data collection and analysis, decision to publish, or preparation of the manuscript.

Copyright: (c) 2021 Mathews E et al. This is an open access article distributed under the terms of the Creative Commons Attribution License, which permits unrestricted use, distribution, and reproduction in any medium, provided the original work is properly cited.

How to cite this article: Mathews $E$, Sauzet $O$ and Thankappan KR. Effectiveness of a physical activity intervention program using peer support among sedentary women in Thiruvananthapuram City, India: results of a non-randomized quasi experimental study [version 1; peer review: 3 approved] Wellcome Open Research 2021, 6:87 https://doi.org/10.12688/wellcomeopenres.16618.1

First published: 20 Apr 2021, 6:87 https://doi.org/10.12688/wellcomeopenres.16618.1 


\section{Introduction}

Physical inactivity accounted for 1.3 million deaths in 2017 globally (GBD, 2017). Physical inactivity, a major risk factor for death and disability due to non-communicable diseases (NCDs) (Lee et al., 2012) has been found to be higher among women $(33.9 \%)$ than in men $(27.9 \%)$ worldwide (Bauman et al., 2012). In Kerala, the most advanced Indian state in epidemiological transition, women were reported to have higher prevalence of NCDs and risk factors such as physical inactivity (Shah \& Mathur, 2010; Thankappan et al., 2010) and overweight (IIPS, 2008). Culture and gender norms have restricted women from engaging in leisure time physical activity (PA) such as brisk walking and other moderate intensity sports (Mathews et al., 2016). A declining trend in physical activity at work and transportation was reported (Shah \& Mathur, 2010) among women due to increased mechanization and urbanization.

Promotion of physical activity through community-based activities using informational, behavioral, social, policy and environmental approaches have been well advocated and reported to be effective in developed nations (Baker et al., 2011). Interventions using informational approaches have used point of decision prompts (Brownell et al., 1980), community wide (Roux et al., 2008) and mass media campaigns (Bauman et al., 2001). Interventions using behavioral and social approaches have used individually adapted stage targeted interventions (Marcus et al., 1998), behavioral modification education (Calfas et al., 2000), behavioral modification counselling (Glasgow et al., 2001), physician based counselling (Calfas et al., 2002), telephonic counselling (Green et al., 2002), web based counselling (De Vries \& Brug, 1999), social support interventions (Amorim et al., 2010) and family/home based interventions (Stephens et al., 1985). Interventions using the environmental approach have focused on creating or enhancing access to places for physical activity (Mohan et al., 2006), use of community scale urban design and land use policies (Aytur et al., 2007), transportation policy and infrastructure change (Aytur et al., 2007) and community wide policies and planning (Hoehner et al., 2008).

Most of these interventions were developed and implemented in high resource settings where there was adequate infrastructure and systems to support behaviour change, with information and support provided on a one to one or group basis laying the responsibility of making a behavior change on the individuals themselves, whether it was diet, physical activity or quitting alcohol and tobacco. However, in developing countries such as India, where the systems support in terms of health professionals, health systems and socio-environmental conditions are very limited, an individualistic approach to behavioral management is quite challenging and difficult to sustain.

Evidence suggests that support from friends, neighbors, and spouses play a crucial role in being physically active (Mathews et al., 2015). Recent advances in chronic disease care and management show that peer support enables people to share their experiences and provides the practical, emotional, and ongoing support that are critical to sustained behavior change (Boothroyd $\&$ Fisher, 2010). Several studies have utilized the concept of peer support in diabetes management (Philis-Tsimikas et al., 2004), arthritis care (Barlow et al., 2000), mental health (Davidson et al., 2006) and self-directed behavior change (Keyserling et al., 2002). In India, peer support has been found to play an important role in chronic disease management (Aswathy et al., 2013) and could be considered as a viable strategy to promote physical activity among women in India as social support from peers plays a crucial role in overcoming the individual level constraints and barriers related the gender and cultural norms (Eger et al., 2018).

Research on physical activity interventions is limited in India. Intervention studies have mostly focussed on lifestyle modification, specifically diabetes prevention (Ramachandran et al., 2001; Satish et al., 2013). However, there have been no intervention studies reported from India with the primary aim of promoting physical activity among adults, specifically women. Given the higher risk for women in developing chronic diseases and the inherent nature of women having fewer opportunities to be active, an intervention trial was conducted to promote physical activity among sedentary women in Thiruvananthapuram city, using peer support. The objective of the study was to assess the effectiveness and sustainability of a culturally specific intervention using peer support in increasing the proportion of physically active women in the intervention arm when compared to the control arm after one year of intervention.

\section{Methods}

\section{Ethical approval}

Ethical approval for this study was obtained from the Institute Ethics committee of Sree Chitra Tirunal Institute for Medical Sciences and Technology, Trivandrum (approval number: SCT/IEC/383/NOVEMBER-2011 dated 28.11.2011) and have been performed in accordance with the ethical standards as laid down in the 1964 Declaration of Helsinki and its later amendments or comparable ethical standards. The trial was registered in the Clinical Trials Registry of India (CTRI registration number: CTRI/2011/12/002222 [registered on 13.12.2011]). Written informed consent was obtained from all individual participants included in the study.

\section{Study settings}

Thiruvananthapuram district of Kerala has a similar human development index and literacy rate to that of the state as a whole (Government of Kerala, 2005). This study was conducted in the expanded part of Thiruvananthapuram City which constitutes the five erstwhile "Panchayats" (lowest administrative unit of local self-government) added to the city corporation in the year 2010 due to their proximity to the city and other developmental activities in these regions. These five erstwhile Panchayats were chosen for the study due to feasibility. The newly added erstwhile panchayats constituted 14 wards of the 100 wards in the Thiruvananthapuram City Corporation.

\section{Study design}

This study followed a non-randomized quasi- experimental study design with a comparison group. The intervention was for a period of 6 months with 3 months of intense phase and another 3 months of less intense phase. Multi- level 
engagement of varying intensities was delivered targeting community, participants and peer leaders. At the community level, the office bearers of residents' associations and self-help women's group were briefed on the need and nature of the intervention, and sought support, both for logistics and structural changes. Study participants were engaged in individual NCD risk assessment through a medical camp, educational workshop, group counselling sessions, peer leader led sessions for goal setting and goal review, participant handbook and guided culturally appropriate activities of choice such as group /individual walking and/or aerobic dance sessions. A peer leader, amongst the participants in each cluster was identified, trained and given ongoing support for group mentoring. Intervention at all the levels were delivered of varying intensity (Table 1). The control participants received printed information materials on non-communicable diseases and their risk factors.

\section{Sample size estimation}

Sample size was estimated with the anticipated assumption that $30 \%$ (Prince et al., 2014) of participants in the intervention arm would meet the physical activity recommendations compared to $10 \%$ in the control arm after the intervention trial. In order to detect the $20 \%$ difference in the proportion of people achieving the WHO PA recommendations (at least 150 minutes of moderate-intensity aerobic PA throughout the week or at least 75 minutes of vigorous-intensity aerobic PA throughout the week, or an equivalent combination of moderate- and vigorous-intensity activity) (WHO GPAQ) between the intervention and control arm with a confidence level of $95 \%$ and a power of $80 \%$, the sample size required was 94 (Smith \& Morrow, 1996). Considering a loss to follow up of $6 \%$ and a design effect of two for the cluster sampling, a sample of 200 in each arm $(n=400)$ was to be enrolled into the trial. Based on an anticipated physical inactivity prevalence of $31.8 \%$ among women aged 15-64 years (Satish, 2008), the survey had to be conducted among at least 1258 women [(100/31.8)*400=1258)] in order to get 400 sedentary women for the intervention trial.

\section{Sample selection process}

The sample consisted of sedentary women. The sample selection scheme is shown in Figure 1. The sample was selected from the residents' associations of the two selected panchayats, which enrolled over $95 \%$ of the households. Each residents' association had a number of households varying from 25 to 250 with an average number of 93 . Out of 71 residents' associations in these two panchayats, $14(1258 / 93=14)$ were randomly selected through random number generator in Microsoft excel (seven each in the intervention and control arms) initially in order to get the sample size of 1258 women. An additional two residents' associations were similarly selected to ensure an adequate sample for the intervention trial.

Sedentary women for this trial was identified through a house to house survey using a structured interview schedule by the trained data collectors (Mathews et al., 2015). The interview

Table 1. Phases of the intervention.

\begin{tabular}{|c|c|c|c|}
\hline $\begin{array}{l}\text { Level of } \\
\text { intervention }\end{array}$ & Intense phase & Less intense phase & No intervention phase \\
\hline Community & $\begin{array}{l}\checkmark \text { Community mobilization } \\
\checkmark \text { Engagement with the stake } \\
\text { holders } \\
\checkmark \text { Community ownership of the } \\
\text { program }\end{array}$ & $\begin{array}{l}\checkmark \text { Participation in community } \\
\text { events such as annual day } \\
\checkmark \text { Advocacy at events }\end{array}$ & $\begin{array}{l}\checkmark \text { Community } \\
\text { initiatives for } \\
\text { sustainment }\end{array}$ \\
\hline Participants & $\begin{array}{l}\checkmark \text { Individual NCD risk } \\
\text { assessment through medical } \\
\text { camps: assessment of waist } \\
\text { circumference, body mass } \\
\text { index and blood pressure. } \\
\checkmark \text { Educational workshop } \\
\checkmark \text { Group counselling } \\
\checkmark \text { Goal setting and goal review } \\
\checkmark \text { Participant handbook } \\
\checkmark \text { Group walking } \\
\checkmark \text { Aerobic dance sessions }\end{array}$ & $\begin{array}{l}\checkmark \text { Goal setting and review } \\
\checkmark \text { Peer leader led meetings } \\
\text { within the group } \\
\checkmark \text { Supporting and motivating } \\
\text { the participants to sustain the } \\
\text { behavioral change } \\
\checkmark \text { Continuing group-based } \\
\text { activities }\end{array}$ & $\begin{array}{l}\checkmark \text { Self-monitoring of } \\
\text { the behavior }\end{array}$ \\
\hline Peer leaders & $\begin{array}{l}\checkmark \text { Peer leader selection } \\
\checkmark \text { Peer leader training and } \\
\text { capacity building to assist the } \\
\text { group in behavioral change } \\
\checkmark \text { Peer leader and participant } \\
\text { workbook }\end{array}$ & $\begin{array}{l}\checkmark \text { Organizing meeting within and } \\
\text { outside the group } \\
\checkmark \text { Organize walking groups } \\
\checkmark \text { Support the participants in } \\
\text { making behavioral change }\end{array}$ & \\
\hline
\end{tabular}


Two out of five panchayats recently added to Thiruvananthapuram
Corporation identified as intervention and control based on similar socio-
demographic features and non-contiguous nature

\section{Wave 1 screening}

\begin{tabular}{l}
$\begin{array}{l}\text { Total number of } \\
\text { households }\end{array}$ \\
$\begin{array}{l}\text { Total number of } \\
\text { participants surveyed }\end{array}$ \\
\hline
\end{tabular}

Number of people

1735 households (14 residents association) (919-Intervention arm, 816-control arm)

1303 participants

(660-Intervention,643-control arm)

346 participants(179-Intervention arm, 167, control arm)

\section{Wave 2 screening}

\begin{tabular}{l}
$\begin{array}{l}\text { Total number of } \\
\text { households }\end{array}$ \\
$\begin{array}{l}\text { Total number of } \\
\text { participants surveyed }\end{array}$ \\
$\begin{array}{l}\text { Number of people } \\
\text { identified sedentary }\end{array}$ \\
\hline
\end{tabular}

186 households( 2 residents association) (75-Intervention arm, 111-control arm)

183 participants
(74-Intervention,109-control arm)
Overall Response

rate: $75.1 \%$

( I-71.8\%,C-78.7\%)

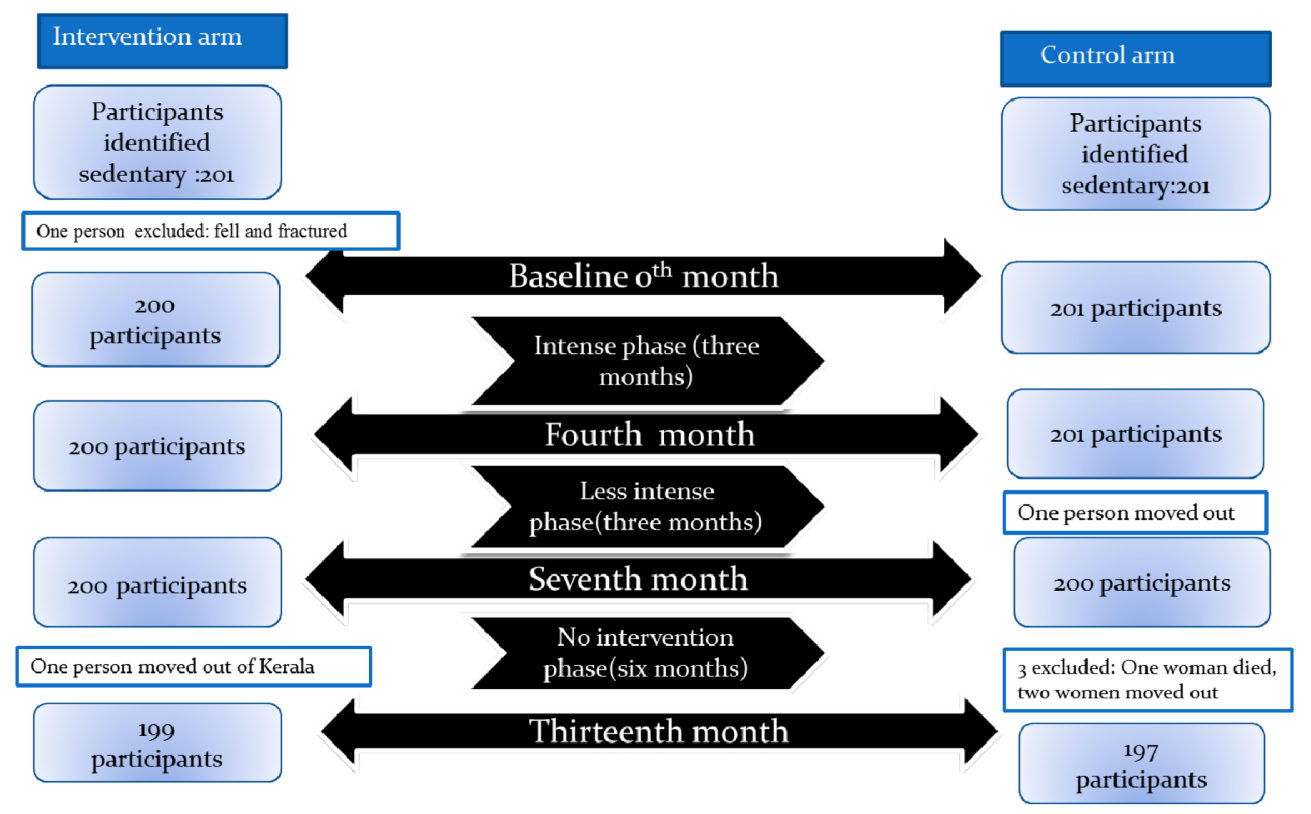

Figure 1. Schematic representation of the selection of the study sample.

schedule consisted of socio-demographic information, selfreported physical activity assessed through Global Physical Activity Questionnaire (GPAQ), and factors influencing physical activity. All households within the residents' association were surveyed. Those women who consented were included in the survey. Women with physical deformities, those who were bedridden, those who were pregnant and lactating, those who were less likely to reside in the area for the next 6 months, and those with disease conditions where PA was contraindicated were excluded from the survey. In wave 1 screening, 1303 participants were identified from 1735 households and in wave 2 screening, 183 participants were surveyed from 186 households. Locked houses were excluded if they remained locked the second time of visit, and in instances of more than one eligible woman per 
household, one was selected randomly. We identified 402 women as sedentary. All women identified as sedentary and willing to participate in the trial were subsequently enrolled.

\section{Data collection techniques}

Data collection and entry were done by trained voluntary workers at the community using an interview schedule. Data captured at the household included socio-demographic information, physical activity assessment, and factors influencing PA at individual, family and community level (Mathews et al., 2015). Physical activity level of the women was assessed using the Global Physical Activity Questionnaire (GPAQ), validated in India (Bull et al., 2009). GPAQ captures physical activity from three domains - work, transport and leisure. Women with a total physical activity level of $<600,600-2999$, and $\geq 3000$ metabolic equivalent task (MET) minutes per week were classified into low (sedentary), moderate, and high PA levels respectively (Bull et al., 2009).

At the baseline, apart from the self-reported physical activity, anthropometric assessments including height, weight and waist circumference were taken at the NCD risk assessment mobile clinic organised in each residents' association by two trained medical professionals (a medical doctor and the PI, who is a trained nurse). Anthropometric measurements were taken using standard equipment and protocol (WHO, 2005).

Similarly, physical activity as measured by the GPAQ, physical activity behaviour, and facilitators and barriers in PA engagement were made at fourth, seventh and thirteenth month of intervention. At the fourth and thirteenth month of intervention, anthropometric measurements were taken at the individuals' household by the same data collector. Data collectors were blinded to the study groups.

\section{Intervention development}

Intervention development adhered to the intervention mapping protocol (Bartholomew et al., 1998). The physical activity goal was derived from the WHO global strategy for diet and physical activity (WHO, 2014). Intervention components were identified based on the findings from the formative research which included focus group discussions (Mathews et al., 2016) and a cross-sectional survey (Mathews et al., 2015), and was supported by some theories of health promotion. In this previous research, focus group discussions among women residents captured the perceptions on barriers and facilitators of physical activity. Lack of knowledge/ awareness on the physical activity recommendations, benefits of PA, activities to engage and misperceptions on the intensity of activities were key findings. Participants also stated that they need company to engage in any outdoor PA. The positive correlates of PA from the cross-sectional survey were knowledge on benefits of PA and support from friends and neighbours.

Based on the findings, intervention aimed to address the gap in knowledge through educational workshop, increase selfawareness on the impending risk associated with the sedentary lifestyle through NCD risk assessment mobile camps, enhance social support through group counselling and peer support, and engage in sustainable behaviour change through application of behavioural theories of reasoned action and planned behaviour, social cognitive theory, enhancing self-efficacy and peer support.

Figure 2 describes the processes that lead to the identification of the intervention components.

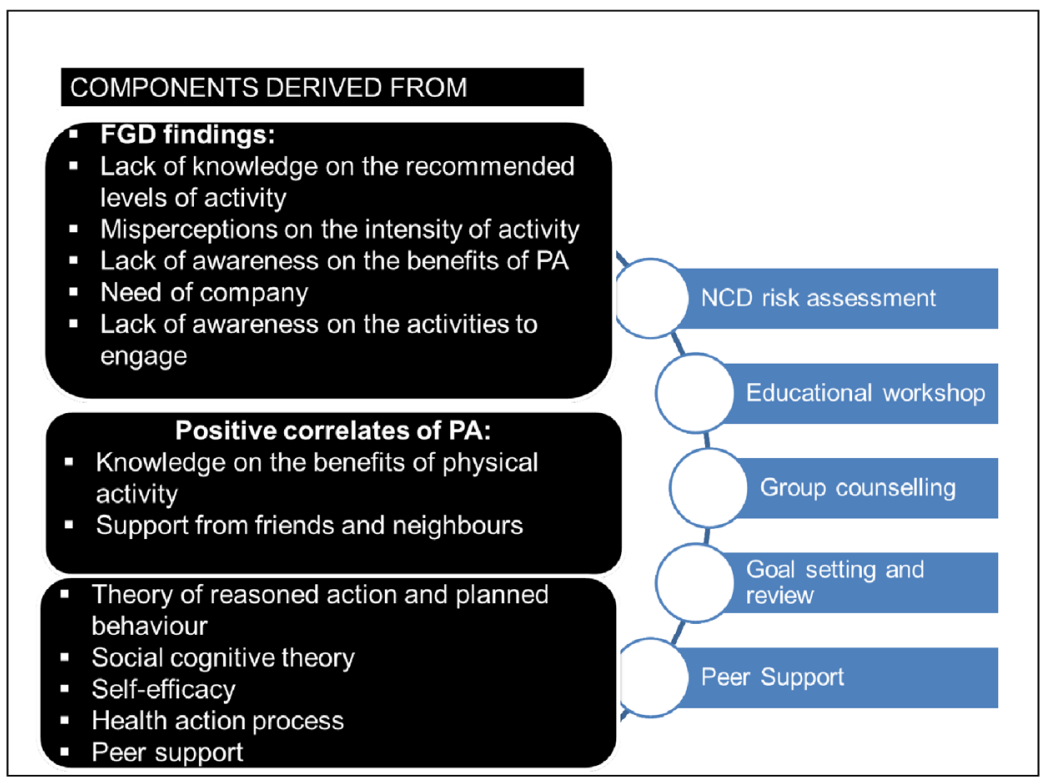

Figure 2. Processes involved in the identification of the intervention components. 
Phases of intervention delivery at multiple levels

Informed written consent was obtained from the participant at the baseline survey for participation in the study. Subsequent to being identified as sedentary, their willingness to participate in the trial was sought. Among 402 women identified as sedentary, 401 women consented to further participate in the trial.

Table 1 shows the phases of intervention with activities at different levels - community, peer leader and participants. The intervention was delivered in three phases: the first three months of an "intense" phase, the next three months of a "less intense" phase and the latter six months of a "no intervention" phase.

\section{a. Intense Phase of Intervention (0-3 months)}

At the community level, activities were focused on community mobilization, which involved, preliminary stakeholder meetings with the local women's self-help group (Kudumbashree) and the office bearers of residents' association for rapport, support and ownership of the program. This has led to strong support in facilitating the organization of mobile camps for NCD risk assessment in the neighbourhood and conduct of regular peer led meetings. Subsequently, discussions were held on making the local area physical activity friendly to overcome the stray dog menace and converting "dead use" land to walking paths.

At the participant level, activities included NCD risk assessments, educational workshops and peer group meetings within each cluster. Women identified as sedentary had NCD risk assessment at the mobile camps organised in their neighbourhood, where blood pressure and anthropometric assessments were done. On the same day, an educational workshop was conducted to raise awareness on NCDSs, physical activity, its benefits and the recommendation for health benefits.

Participants were provided with a handbook which consisted of two Units. Unit 1 focussed on physical activity and health, and included the following contents: importance of physical activity, change in the lifestyle over generations, types and benefits of physical activity, role of physical activity in preventing premature mortality, diabetes mellitus, cardiovascular diseases, stroke and other non-communicable diseases, improved mental health, and recommendations of PA for health benefits by World Health Organization (WHO). Unit 2 focussed on practical components to assist the participants in behaviour change. It included locally relevant activities of moderate-vigorous intensities, identifying facilitators and barriers, goal setting, mapping the locality for activities that are pursuable, and goal reviews in peer leader meetings. Regular fortnightly meetings with the women participants were organised in the households of these women members to discuss on the progress of achieving individual level physical activity goals. Within each residents' association, a peer leader was identified and trained for five days on mentoring, communication skills and contents of the peer leader handbook. The initial three meetings were led by the PI in the presence of the peer leaders. Subsequently, the peer leaders conducted the meetings and contacted the Principal
Investigator to update on the progress of the meetings. The average participation rate was $70 \%$ in the intense phase of intervention.

The less intense phase involved peer leader led sessions to support and motivate participants to sustain physical activity behaviour change, with no PI involvement. During the no intervention phase, no active engagement was made with the intervention groups. However, informal gatherings took place.

Participants in the control arm were provided with educational booklets on chronic diseases at the baseline and no engagements were made thereafter apart from the $4^{\text {th }}, 7^{\text {th }}$ and $13^{\text {th }}$ month assessments. All study materials can be found as extended data (Mathews, 2021).

\section{Variables}

The outcome variable is the physical activity measured using GPAQ quantified in MET minutes per week. The independent variables were age (completed years), educational status, occupation, marital status and anthropometric measures such as height, weight and waist circumference. Participants were asked to report on the activities undertaken to achieve the recommended levels of activity, the facilitators and barriers of physical activity. Participants were asked to rate the aspects of intervention that motivated to take up the activity such as peer supporters, group counselling, support from family, support from neighbours, being part of the group and the information booklet.

\section{Data analysis}

Data were analyzed using STATA version 11.2 and SPSS version 17. Data from the GPAQ were scored using SPSS version 17 (IBM Corp). The GPAQ data on physical activity were quantified as MET minutes per week and were derived by adding the products of intensity (MET), duration (minutes) and frequency (number of times per week) of each of the reported work-related, travel-related, and leisure-related physical activities. A value of 4 METs was assigned for moderate intensity activity and a value of 8 METs was assigned for vigorous intensity activity. Domain specific scores on work, transport and leisure were calculated to understand the changes made in each domain. Individuals with missing data were excluded from the analysis.

The chi-square test was done to examine whether the baseline parameters such as age, educational status, occupation and marital status were significantly different between the intervention and control arms. Multilevel mixed model analysis was done to assess the intervention effectiveness in terms of physical activity energy expenditure during the study period after considering the effect of time, clusters and groups, and considered the non-independence of observations within patient and patient within clusters. Longitudinal data analysis considered individual, cluster, groups and time point at four levels. Study participants were referred to as individuals. Cluster was referred to the cluster sampling design adopted in the study and there were eight clusters each in the intervention and control arm. Group referred to the intervention and control arms of the intervention 
trial. Time referred to in the model was the multiple time points at which assessments were made namely baseline, fourth, seventh and thirteenth months. The effect of the intervention was analysed at two levels in the model. The difference in the mean level of physical activity between the intervention and the control arm at each time point was estimated using timegroup interaction with time being a dummy variable. The improvement in physical activity level from baseline due to effect of intervention at each time when compared to the control arm was estimated using time-group interaction with time as a continuous variable (Sauzet et al., 2015). The effect of confounding for age, educational status, occupational status and marital status was eliminated in the analysis by including those variables in the model with the level of significance at ' $p$ ' value of 0.1 between the intervention and control arm. Distribution of age and occupation was significantly different between the intervention and control arms with a ' $p$ ' value of 0.1 and hence was included in the model.

\section{Results}

A total of 401 women (intervention - 200, control - 201) were enrolled in the trial at the baseline. At the end of $13^{\text {th }}$ month, five women dropped out. The detailed participant flow chart is given in Figure 1. The mean age of the study participants in the intervention arm was 48 years (SD 0.72) and 46 years (SD 0.86) in the control arm. Table 2 describes the baseline characteristics of the study sample population (Mathews, 2021).

Table 3 describes the physical activity pattern of study participants at multiple time points. At the $4^{\text {th }}$ month, after intense phase of intervention, $58.5 \%$ of women were found to be active in the intervention arm compared to $10 \%$ active women in the control arm ( $\mathrm{p}$ value-0.001). At the seventh month, subsequent to a three month less intense phase of intervention, $48.5 \%$ of women were found to be active in the intervention arm compared to $6 \%$ in the control arm. With no intervention for a period of six months, the proportion of active women was $29.6 \%$ in the intervention arm compared to $0.6 \%$ in the control arm.

Table 4 describes the mean levels of physical activity, body mass index (BMI) and waist circumference in both intervention and the control arms at multiple time points.

Women rated group counseling, social support from family, and peer support as important intervention components that motivated for being active. Table 5 shows the modelled estimate of physical activity level in the intervention and control arms at fourth, seventh and thirteenth month. The coefficient of change was the amount of physical activity expended at each time point when compared to the baseline. The coefficient of change (MET minutes per week) from baseline was significantly higher in the intervention arm compared to the control arm at $4^{\text {th }}$ month (1075.02 vs 82.96$)$, $7^{\text {th }}$ month $(623$ vs 47.68$)$ and thirteenth month (441.02 vs -25.45$), \mathrm{p}=<0.001$.

Domain specific progress in the intervention arm at multiple points (Figure 3) were analysed. Much of the physical activity (MET min/week) reported after the intense phase of intervention was in transportation and work compared to leisure (558.2 vs 409.8 vs 191.2). However, at the $7^{\text {th }}$ month, leisure time PA

Table 2. Baseline characteristics of the sample.

\begin{tabular}{|c|c|c|c|}
\hline Categories & $\begin{array}{l}\text { Intervention arm }(n=200) \\
N(\%)\end{array}$ & $\begin{array}{l}\text { Control arm }(n=201) \\
N(\%)\end{array}$ & P value* \\
\hline \multicolumn{4}{|l|}{ Age group (years) } \\
\hline$<35$ & $025(12.5)$ & $047(23.4)$ & \multirow[t]{3}{*}{0.001} \\
\hline 35- 54 & $117(58.5)$ & $086(42.8)$ & \\
\hline $55+$ & 058(29.0) & 068(33.8) & \\
\hline \multicolumn{4}{|l|}{ Education status } \\
\hline Up to high school & $104(52.0)$ & $100(49.7)$ & \multirow[t]{2}{*}{0.6} \\
\hline Higher secondary and above & 096(48.0) & 101(51.3) & \\
\hline \multicolumn{4}{|l|}{ Current Occupational status } \\
\hline Employed & $031(15.5)$ & $051(25.4)$ & \multirow[t]{2}{*}{0.01} \\
\hline Unemployed** & 169(84.5) & $150(74.6)$ & \\
\hline \multicolumn{4}{|l|}{ Marital status } \\
\hline Married & 179(89.5) & $170(84.6)$ & \multirow[t]{2}{*}{0.2} \\
\hline Others*** & $021(10.5)$ & 031(15.4) & \\
\hline
\end{tabular}

*Chi square $\mathrm{p}$ value comparing the proportion between intervention and control arm.

**Housewives, retired, unemployed and students, ***Unmarried, separated, divorced and widowed 
Table 3. Physical activity pattern over multiple time points.

\begin{tabular}{|c|c|c|c|c|c|c|}
\hline Time point & $\begin{array}{l}\text { Activity } \\
\text { levels }\end{array}$ & $\begin{array}{l}\text { Number in the } \\
\text { intervention arm }\end{array}$ & $\begin{array}{l}\text { Intervention arm } \\
\mathbf{N}(\%)\end{array}$ & $\begin{array}{l}\text { Number in the } \\
\text { control arm }\end{array}$ & $\begin{array}{l}\text { Control arm } \\
\mathrm{N}(\%)\end{array}$ & P value* \\
\hline \multirow[t]{2}{*}{ Baseline } & Inactive & \multirow{2}{*}{200} & $200(100)$ & \multirow[b]{2}{*}{201} & $201(100)$ & \\
\hline & Active & & $000(000)$ & & $000(000)$ & \\
\hline \multirow[t]{2}{*}{$4^{\text {th }}$ month } & Inactive & \multirow{2}{*}{200} & $083(41.5)$ & \multirow{2}{*}{201} & $180(90.0)$ & \multirow[t]{2}{*}{0.001} \\
\hline & Active & & $117(58.5)$ & & $021(10.0)$ & \\
\hline \multirow[t]{2}{*}{$7^{\text {th }}$ month } & Inactive & \multirow{2}{*}{200} & $103(51.5)$ & \multirow{2}{*}{200} & $188(94.0)$ & \multirow[t]{2}{*}{0.001} \\
\hline & Active & & $097(48.5)$ & & $012(06.0)$ & \\
\hline \multirow[t]{2}{*}{$13^{\text {th }}$ month } & Inactive & \multirow{2}{*}{199} & $140(70.4)$ & \multirow{2}{*}{197} & 196 (99.4) & \multirow[t]{2}{*}{0.001} \\
\hline & Active & & 059 (29.6) & & 001 (00.6) & \\
\hline
\end{tabular}

${ }^{*}$ Chi square $p$ value comparing the proportion between intervention and control arm.

\begin{tabular}{|c|c|c|c|c|c|}
\hline $\begin{array}{l}\text { Time } \\
\text { point }\end{array}$ & Parameters & $\begin{array}{l}\text { Number of } \\
\text { women in the } \\
\text { intervention } \\
\text { arm }\end{array}$ & $\begin{array}{l}\text { Intervention } \\
\text { arm } \\
\text { Mean (SD) }\end{array}$ & $\begin{array}{l}\text { Number of } \\
\text { women in } \\
\text { the control } \\
\text { arm }\end{array}$ & $\begin{array}{l}\text { Control } \\
\text { arm } \\
\text { Mean (SD) }\end{array}$ \\
\hline \multirow{3}{*}{ Baseline } & Body mass index (kg/m²) & 200 & $\begin{array}{l}26.96 \\
(3.80)\end{array}$ & 201 & $\begin{array}{l}26.72 \\
(5.11)\end{array}$ \\
\hline & Waist circumference (cm) & 200 & $\begin{array}{l}89.81 \\
(9.09)\end{array}$ & 201 & $\begin{array}{l}87.90 \\
(11.64)\end{array}$ \\
\hline & $\begin{array}{l}\text { Physical activity level } \\
\text { (MET minutes per week) }\end{array}$ & 200 & $\begin{array}{l}84.30 \\
(152.51)\end{array}$ & 201 & $\begin{array}{l}120.60 \\
(179.99)\end{array}$ \\
\hline \multirow{3}{*}{$4^{\text {th }}$ month } & Body mass Index $\left(\mathrm{kg} / \mathrm{m}^{2}\right)$ & 200 & $\begin{array}{l}26.85 \\
(3.78)\end{array}$ & 201 & $\begin{array}{l}26.85 \\
(5.12)\end{array}$ \\
\hline & $\begin{array}{l}\text { Waist circumference } \\
(\mathrm{cm})\end{array}$ & 200 & $\begin{array}{l}89.62 \\
(8.97)\end{array}$ & 201 & $\begin{array}{l}88.04 \\
(11.62)\end{array}$ \\
\hline & $\begin{array}{l}\text { Physical activity level } \\
\text { (MET minutes per week) }\end{array}$ & 200 & $\begin{array}{l}1159.22 \\
(1065.60)\end{array}$ & 201 & $\begin{array}{l}202.19 \\
(314.00)\end{array}$ \\
\hline $7^{\text {th }}$ month & $\begin{array}{l}\text { Physical activity level } \\
\text { (MET minutes per week) }\end{array}$ & 200 & $\begin{array}{l}707.30 \\
(608.43)\end{array}$ & 200 & $\begin{array}{l}168.26 \\
(310.34)\end{array}$ \\
\hline \multirow{3}{*}{$13^{\text {th }}$ month } & Body mass Index $\left(\mathrm{kg} / \mathrm{m}^{2}\right)$ & 199 & $\begin{array}{l}27.79 \\
(4.08)\end{array}$ & 197 & $\begin{array}{l}27.09 \\
(5.15)\end{array}$ \\
\hline & Waist circumference(cm) & 199 & $\begin{array}{l}89.22 \\
(11.22)\end{array}$ & 197 & $\begin{array}{l}88.09 \\
(11.37)\end{array}$ \\
\hline & $\begin{array}{l}\text { Physical activity level } \\
\text { (MET minutes per week) }\end{array}$ & 199 & $\begin{array}{l}525.93 \\
(547.97)\end{array}$ & 197 & $\begin{array}{l}95.12 \\
(156.63)\end{array}$ \\
\hline
\end{tabular}

MET=metabolic equivalent task; SD=standard deviation

was reported the highest (283.3) compared to transportation (258.4) and work (165.6).

Figure 4 represents the modelled estimate of physical activity level in the intervention arm compared to the control arm at multiple time points. At the fourth month of intervention, women in the intervention arm expended 1075 (95\% CI: 952.661197.30) MET-min / week more than at baseline. The energy expended was 623 (95\% CI: 500.67-745.32) MET-min/ week more in the seventh month of intervention when compared to the baseline. At the thirteenth month of intervention, the energy expended by the women in the intervention arm was 441 


\section{Table 5. Modelled estimate of physical activity level in the intervention and control arms at multiple} time points.

\begin{tabular}{|c|c|c|c|c|}
\hline \multirow[b]{2}{*}{$\begin{array}{l}\text { Time } \\
\text { point }\end{array}$} & \multicolumn{2}{|l|}{ Intervention arm } & \multicolumn{2}{|l|}{ Control arm } \\
\hline & $\begin{array}{l}\text { Coefficient of change } \\
\text { from baseline } \\
\text { (MET minutes per week) } \\
\text { (95\% CI) }\end{array}$ & $\begin{array}{l}\text { Mean physical } \\
\text { activity* } \\
\text { (MET minutes per } \\
\text { week) } \\
(95 \% \mathrm{CI})\end{array}$ & $\begin{array}{l}\text { Coefficient of change } \\
\text { from baseline } \\
\text { (MET minutes per week) } \\
\text { (95\% CI) }\end{array}$ & $\begin{array}{l}\text { Mean physical } \\
\text { activity* } \\
\text { (MET minutes } \\
\text { per week) } \\
(95 \% \mathrm{CI})\end{array}$ \\
\hline $4^{\text {th }}$ month & $\begin{array}{l}\text { 1075.02** } \\
(952.66-1197.38)\end{array}$ & $\begin{array}{l}1158.90 \\
(942.96-1375.08)\end{array}$ & $\begin{array}{l}82.96 \\
(43.47-122.46)^{\star *}\end{array}$ & $\begin{array}{l}203.36 \\
(129.2-277.67)\end{array}$ \\
\hline $7^{\text {th }}$ month & $\begin{array}{l}623.00 * * \\
(500.67-745.32)\end{array}$ & $\begin{array}{l}706.97 \\
(490.92-923.02)\end{array}$ & $\begin{array}{l}47.68 \\
(08.24-87.12)^{\star}\end{array}$ & $\begin{array}{l}168.08 \\
(93.97-242.19)\end{array}$ \\
\hline $\begin{array}{l}13^{\text {th }} \\
\text { month }\end{array}$ & $\begin{array}{l}441.02 * * \\
(318.53-563.51)\end{array}$ & $\begin{array}{l}524.99 \\
(308.77-741.21)\end{array}$ & $\begin{array}{l}-25.45 \\
(-64.89-13.98)\end{array}$ & $\begin{array}{l}094.95 \\
(20.84-169.05)\end{array}$ \\
\hline
\end{tabular}

Variables in the model: Individual, intervention arm, cluster, and time point. MET=metabolic equivalent task; CI=confidence interval

* Estimated from the model based on the linear mixed effect model

$* \star P$ value for the coefficient of change from the baseline significant at $<0.001$ level

* $\mathrm{P}$ value for the coefficient of change from the baseline significant at 0.01 level

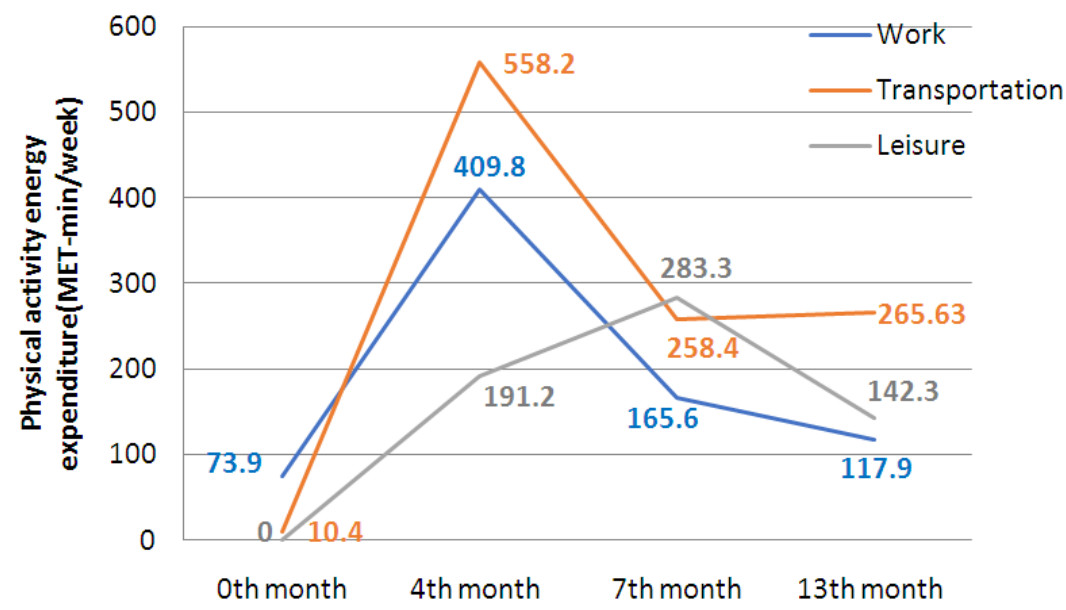

Figure 3. Domain specific progress in the intervention arm at multiple points.

(95\% CI: 318.53-563.51) MET-min/ week more when compared to the baseline.

The analysis showed that the intervention arm had more physical activity compared to the control arm at all the three time points: at month four, 992 (SD: 65) MET minutes per week more than the control arm, at month seven, 575 (SD: 65) MET minutes per week more than the control arm and at month 13, 466 (SD: 65) MET minutes per week more than the control arm.

\section{Discussion}

Promotion of physical activity among sedentary women in Thiruvananthapuram city using peer support was found to be effective during the study period. The highest proportion of active women during the study period was after the three months' intense phase in the intervention arm when compared to the control arm $(58.5 \%$ vs $10 \%)$. This could be due to the intense nature of the intervention. The educational workshop sensitized the women on several dimensions such as recognizing the importance of physical activity, intensities of activity needed for health benefit especially for chronic disease prevention, breaking the misperception of adequacy of physical activity from household work and setting up realistic and feasible goals with the support of group members. Group based activities including walking groups have also been found to be beneficial in other studies where a walking program among elderly cancer survivors showed 


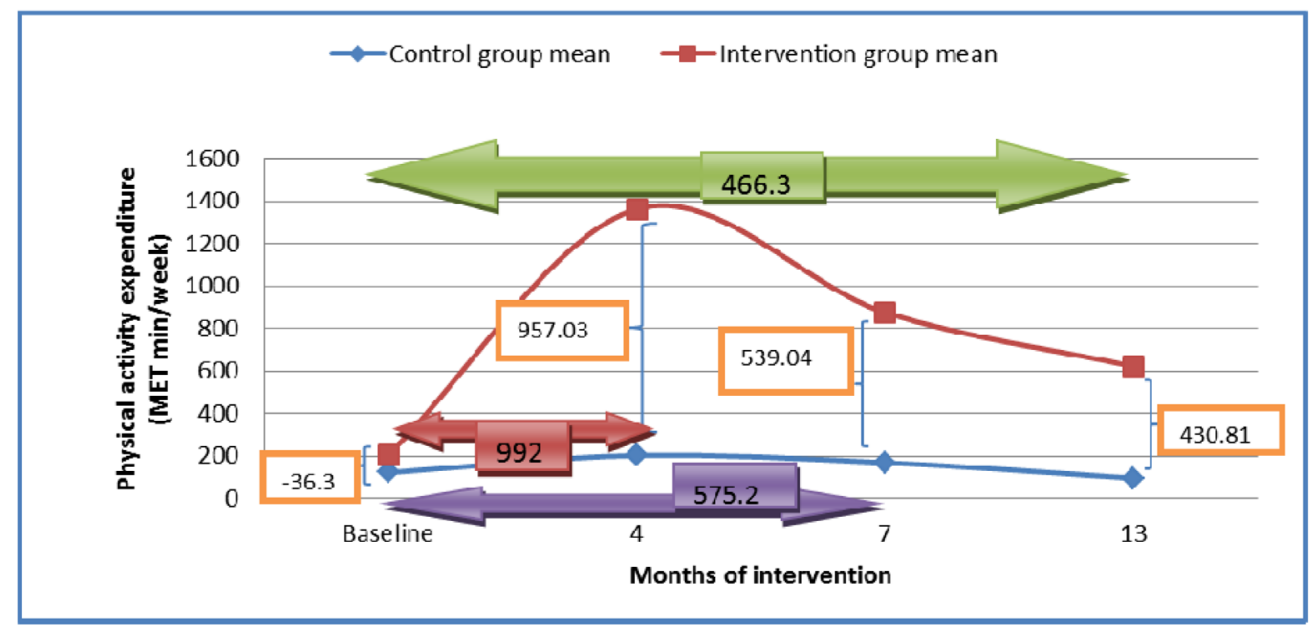

\footnotetext{
$\square$ Depicts the difference in the mean level of physical activity between the intervention and control arm at each time point
$\Rightarrow$ The improvement from baseline in amount of physical activity expended by the intervention arm when compared to the control arm at each time point

Figure 4. Modelled estimate of physical activity level in the intervention arm compared to the control arm at multiple time points. The orange boxes depict the difference in the mean level of physical activity between the intervention and control arm at each time point. The horizontal arrows show the improvement from baseline in amount of physical activity expended by the intervention arm when compared to the control arm at each time point.

that the proportion of participants walking 150 minutes per week increased from $21 \%$ at the baseline to $50 \%$ over a six-month period (Nyrop et al., 2014).

The proportion of active women decreased gradually after the "intense" phase, based on the assessment made at the seventh month; however, the number of participants who remained active in the intervention arm was significantly higher than the control arm (48.5\% vs $6 \%)$. The decrease could be either due to the reduced intensity of the intervention or reduced sustainability of intervention over time. However, it is supposed that the monthly meetings with the peer leader and peer support from the group-based activity would have facilitated in sustaining the activity among active women. The proportion of active women in our study after six months of intervention $(48.5 \%)$ was lower than another lifestyle intervention study (78\%) in the United States (US) which involved group-based meetings and goal settings (Dunn et al., 1998). Apart from the group-based activities and goal setting, increased access to facilities in the US could have played a role in higher proportion being active after the intervention, than in our setting.

The latter six months of "no intervention" period showed a reduction in the proportion of active women to half $(29.6 \%)$ of the intense phase $(58.5 \%)$. A physical activity promotion study which targeted both sedentary and physically active participants had shown that participants who were already active were more likely to adhere to the intervention and maintain a healthy lifestyle than the sedentary or inactive ones (Bock et al., 2001). The relative proportion of active women was higher in the intervention arm compared to the control arm (29.6\% vs $0.6 \%)$ despite the reduced proportion of active women in the intervention arm with the tapering dose of intervention. The multiple strategies of health behavior theory adopted in this study such as improving self-efficacy through goal setting, goal review, self-monitoring and peer support along with support from family and friends would have facilitated the positive behavior change and its maintenance, as reported in another study (De Greef et al., 2011). Apart from increased self-efficacy through the educational workshop and individualized counselling, social support from peers and family would have played an important role in the sustenance of activity. Group based intervention delivery has been reported as effective among women and more effective than individual or community-based interventions (Cleland et al., 2013). The effect of an intervention may further decrease over time and it is important to devise strategies for periodic prompts and integrate them with existing community-based initiatives.

An increase in the proportion of active women in the control arm could be due to the influence of the educational booklets given to them. The decline in physical activity in the control arm below the baseline level at thirteenth month suggests that 
with no intervention, individuals tend to go back to their initial sedentary state or retrograde further. This calls for the need to initiate physical activity promotion activities in the community in the wake of rising non-communicable diseases and their risk factors (Jeemon et al., 2019).

A majority of the women who became active at fourth, seventh and thirteenth months of intervention were mostly engaged in moderate intensity activity. Studies have shown that women prefer to do moderate intensity activity over vigorous ones (Forbes, 2014) and walking as the most preferred activity (Bélanger et al., 2012). Domain specific mean levels of physical activity suggests that during the intense phase, most changes were made in the transportation domain (558.2 MET min/week) followed by work (409.8) and leisure (191.2). There was as an increase in the moderate intensity activities reported at domestic work. This could be because the majority $(84.5 \%)$ of them were unemployed and housewives. The increased physical activity level in the transportation domain was because most of them chose to walk for shopping and work. Leisure time activities involved walking individually or in groups and aerobic dancing sessions. Not only leisure time physical activity but physical activity in domains particularly transport and work have been found to have numerous health benefits (Samitz et al., 2011).

A dose-response relationship between the intervention and physical activity was found in this study, similar to another study (Rodondi et al., 2006) and the sustained positive behavior change even in the no intervention phase could be due to the effect of social and peer support. A meta-analysis on physical activity promotion interventions targeting women revealed that the mode of intervention delivery was the key factor that determined the intervention's effectiveness. Group based interventions proved more effective in achieving the targets than individually tailored interventions (Cleland et al., 2013).

Group counselling and information booklets were consistently reported by women as facilitators for physical activity in this study which stresses the importance of information dissemination and assistance in goal setting for making physical activity choices. A previous study reported that goal setting and counselling were important intervention component for behavior change (Ries et al., 2014). Sufficient evidence on the effectiveness of counselling by doctors or health care providers in improving physical activity is available (Wattanapisit et al., 2018). However, in countries such as India, with limited health system resources including health care providers such as doctors, it is imperative to render the services of a peer leader in the community for activities of health promotion. As behavior change needs constant assistance and support for adoption and maintenance (Kwasnicka et al., 2016), it is only practical to engage the community with effective use of peer support.

The culture of PA and sport among women in South India differs markedly from that in regions with the most success in PA promotion such as Brazil, US, Australia and Europe which have invested in social capital and the environment for physical activity promotion. A recent study from Brazil reported a decline in age standardized mortality attributed to physical inactivity which could be due to the improvement in physical activity in the country (Silva Das et al., 2020). In order to bridge this gap, it may require concerted action over a period of time, through government and non-governmental organizations to facilitate transferability and better uptake of the interventions.

A limitation of our study was that it was done in the expanded part of the Thiruvananthapuram city and hence the results may not be generalizable to the entire city. Another limitation was that physical activity was assessed using the GPAQ which is self-reported and not validated with objective measures such as accelerometers or pedometers. However, self-reports have been recommended for epidemiological studies with sufficient validity and reliability (Bull et al., 2009)

Our study points out that "single strategy" does not assist women in making a behavior change. Multiple tailored strategies will have to be employed at multiple time points at multiple levels, i.e. improving personal motivation and self-efficacy at personal level, support from family, spouse and peer support at the interpersonal level, and conducive environment for active living at the community level. High political commitment with mobilization of resources is required for addressing physical inactivity described as a global pandemic in a lancet series on physical activity (Kohl et al., 2012)

\section{Data availability}

\section{Underlying data}

Open Science Framework: Peer support interventions to promote physical activity among sedentary women, India. https://doi. org/10.17605/OSF.IO/CK2AP (Mathews, 2021).

This project contains the following underlying data:

- Raw dataset of participant's reported physical activity levels, at baseline, fourth, seventh and thirteenth month of the intervention, as well as anthropometric parameters and intervention components adopted at relevant time points.

\section{Extended data}

Open Science Framework: Peer support interventions to promote physical activity among sedentary women, India. https://doi. org/10.17605/OSF.IO/CK2AP (Mathews, 2021).

This project contains the following extended data:

- Intervention material developed in the vernacular language (Malayalam)

- Consent form (in both Malayalam and English)

- Data collection tool (in both Malayalam and English)

- Variable description

Data are available under the terms of the Creative Commons Attribution 4.0 International license (CC-BY 4.0). 
Amorim TC, Azevedo MR, Hallal PC: Physical activity levels according to physical and social environmental factors in a sample of adults living in South Brazil. J Phys Act Health. 2010; 7 Suppl 2: S204-12.

PubMed Abstract | Publisher Full Text

Aswathy S, Unnikrishnan AG, Kalra S, et al.: Peer support as a strategy for effective management of diabetes in India. Indian J Endocrinol Metab. 2013; 17(1): 5-7

PubMed Abstract | Publisher Full Text | Free Full Text

Aytur SA, Rodriguez DA, Evenson KR, et al.: Promoting active community environments through land use and transportation planning. Am J Health Promot. 2007; 21(4 Suppl): 397-407.

PubMed Abstract | Publisher Full Text

Baker PR, Francis DP, Soares J, et al.: Community wide interventions for increasing physical activity. Cochrane Database Syst Rev. 2011; 13(4): CD008366.

PubMed Abstract | Publisher Full Text

Barlow JH, Turner AP, Wright CC: A randomized controlled study of the Arthritis Self-Management Programme in the UK. Health Educ Res. 2000; 15(6): $665-80$

PubMed Abstract | Publisher Full Text

Bartholomew LK, Parcel GS, Kok, G: Intervention mapping: a process for developing theory- and evidence-based health education programs. Health Educ Behav. 1998; 25(5): 543-63.

PubMed Abstract | Publisher Full Text

Bauman AE, Bellew B, Owen N, et al.: Impact of an Australian mass media campaign targeting physical activity in 1998. Am J Prev Med. 2001; 21(1): $41-7$

PubMed Abstract | Publisher Full Text

Bauman AE, Reis RS, Sallis JF, et al.: Correlates of physical activity: why are some people physically active and others not? Lancet. 2012; 380(9838): 258-71.

PubMed Abstract | Publisher Full Text

Bélanger LJ, Plotnikoff RC, Clark A, et al.: A survey of physical activity programming and counseling preferences in young-adult cancer survivors. Cancer Nurs. 2012: 35(1): 48-54.

PubMed Abstract | Publisher Full Text

Bock BC, Marcus BH, Pinto BM, et al.: Maintenance of physical activity following an individualized motivationally tailored intervention. Ann Behav Med. 2001; 23(2): 79-87.

PubMed Abstract | Publisher Full Text

Boothroyd RI, Fisher EB: Peers for progress: promoting peer support for health around the world. Fam Pract. 2010; 27 Suppl 1: i62-8.

PubMed Abstract | Publisher Full Text

Brownell KD, Stunkard AJ, Albaum M: Evaluation and modification of exercise patterns in a natural environment. Am J Psychiatry. 1980; 137(12): 1540-5. PubMed Abstract | Publisher Full Text

Bull FC, Maslin TS, Armstrong T: Global Physical Activity Questionnaire (GPAQ): Nine Country Reliability and Validity Study. J Phys Act Health. 2009; 6(6): $790-804$

PubMed Abstract | Publisher Full Text

Calfas KJ, Sallis JF, Nichols JF, et al.: Project GRAD: two-year outcomes of a randomized controlled physical activity intervention among young adults. Graduate Ready for Activity Daily . Am J Prev Med. 2000; 18(1): 28-37. PubMed Abstract | Publisher Full Text

Calfas KJ, Sallis JF, Zabinski MF, et al:: Preliminary evaluation of a multicomponent program for nutrition and physical activity change in primary care: PACE+ for adults. Prev Med. 2002; 34(2): 153-61.

PubMed Abstract | Publisher Full Text

Eger C, Miller G, Scarles C: Gender and capacity building: A multi layered study of empowerment. World Development. 2018; 106: 207-219. Publisher Full Text

Cleland V, Granados A, Crawford D, et al.: Effectiveness of interventions to promote physical activity among socioeconomically disadvantaged women: a systematic review and meta-analysis. Obes Rev. 2013; 14(3): 197-212.

PubMed Abstract | Publisher Full Text

Davidson L, Chinman M, Sells D: Peer support among adults with serious mental illness: A report from the field. Schizophr Bull. 2006; 32(3): 443-450. PubMed Abstract | Publisher Full Text | Free Full Tex

De Greef K, Deforche B, Tudor-Locke C, et al.: Increasing physical activity in Belgian Type 2 diabetes patients: a three-arm randomized controlled trial. Int J Behav Med. 2011; 18(3): 188-98.

PubMed Abstract | Publisher Full Text

De Vries H, Brug J: Computer-tailored interventions motivating people to adopt health promoting behaviors: introduction to a new approach. Patient Educ Couns. 1999; 36(2): 99-105.

PubMed Abstract | Publisher Full Text

Dunn AL, Garcia ME, Marcus BH, et al.: Six-month physical activity and fitness changes in Project Active, a randomized trial. Med Sci Sports Exerc. 1998;
30(7): 1076-83.

PubMed Abstract | Publisher Full Text

Forbes C: Physical Activity Preferences for People with Type 2 diabetes. Research Update from Alberta Centre for Active Living. 2014: 21(2). Retrieved 23 July 2014

Reference Source

Glasgow RE, Eakin EG, Fisher EB, et al.: Physician advice and support for physical activity: results from a national survey. Am J Prev Med. 2001; 21(3): 189-96.

PubMed Abstract | Publisher Full Text

GBD 2017 Risk Factor Collaborators: Global, regional, and national comparative risk assessment of $\mathbf{8 4}$ behavioural, environmental and occupational, and metabolic risks or clusters of risks for 195 countries and territories, 1990-2017: a systematic analysis for the Global Burden of Disease Study 2017. Lancet. 2018; 392(10159): 1923-1994.

PubMed Abstract | Publisher Full Text | Free Full Text

Government of Kerala: Local Self Government Department. 2005; Retrieved 19 September 2013.

Green BB, McAfee T, Hindmarsh M, et al.: Effectiveness of telephone support in increasing physical activity levels in primary care patients. Am J Prev Med. 2002; 22(3): 177-83.

PubMed Abstract | Publisher Full Text

Hoehner CM, Soares J, Perez DP, et al.: Physical activity interventions in Latin America: A systematic review. Am J Prev Med. 2008; 34(3): 224-233.

PubMed Abstract | Publisher Full Text

International Institute for Population Sciences (IIPS) and Macro International: National Family Health Survey (NFHS-3), India, 2005-06: Kerala. Mumbai: IIPS. 2008; Retrieved 15 June 2013.

Reference Source

Jeemon $\mathrm{P}$, Mathews $\mathrm{E}$, Jha V: Non Communicable Diseases: A modern condition? Nature India. 2019; Published online 14 May 2019.

Reference Source

Keyserling TC, Samuel-Hodge CD, Ammerman AS, et al.: A randomized tria of an intervention to improve self-care behaviors of African-American women with type 2 diabetes: impact on physical activity. Diabetes Care 2002: 25(9): 1576-83.

2002; 25(9): 1576-83.

PubMed Abstract | Publisher Full Text

Kohl HW 3rd, Craig CL, Lambert EV, et al.: The pandemic of physical inactivity: global action for public health. Lancet. 2012; 380(9838): 294-305.

PubMed Abstract | Publisher Full Text

Kwasnicka D, Dombrowski SU, White M, et al.: Theoretical explanations for maintenance of behaviour change: a systematic review of behaviour theories. Health Psychol Rev. 2016; 10(3): 277-296.

PubMed Abstract | Publisher Full Text | Free Full Text

Lee IM, Shiroma EJ, Lobelo F, et al.: Effect of physical inactivity on major noncommunicable diseases worldwide: an analysis of burden of disease and

life expectancy. Lancet. 2012; 380(9838): 219-29.

PubMed Abstract | Publisher Full Text | Free Full Text

Mathews E: Peer support interventions to promote physical activity among sedentary women, India. 2021.

http://www.doi.org/10.17605/OSF.IO/CK2AP

Mathews E, Lakshmi JK, Ravindran TKS, et al.: Perceptions of barriers and facilitators in physical activity participation among women in Thiruvananthapuram city, India. Glob Health Promot. 2016; 23(4): 27-36. PubMed Abstract | Publisher Full Text | Free Full Text

Mathews E, Pratt M, Jissa VT, et al.: Self-reported physical activity and its correlates among adult women in the expanded part of Thiruvananthapuram City, India. Indian J Public Health. 2015; 59(2): 136-40. PubMed Abstract | Publisher Full Text | Free Full Text

Marcus BH, Emmons KM, Simkin-Silverman LR, et al: Evaluation of motivationally tailored vs. standard self-help physical activity interventions at the workplace. Am J Health Promot. 1998; 12(4): 246-53. PubMed Abstract | Publisher Full Text

Mohan V, Shanthirani CS, Deepa M, et al.: Community empowerment--a successful model for prevention of non-communicable diseases in India-the Chennai Urban Population Study (CUPS-17). J Assoc Physicians India. 2006. 54: 858-62.

PubMed Abstract

Nyrop KA, Muss HB, Hackney B, et al.: Feasibility and promise of a 6-week program to encourage physical activity and reduce joint symptoms among elderly breast cancer survivors on aromatase inhibitor therapy. J Geriatr Oncol. 2014; 5(2): 148-55.

PubMed Abstract | Publisher Full Text

Prince SA, Saunders TJ, Gresty K, et al.: A comparison of the effectiveness of physical activity and sedentary behaviour interventions in reducing sedentary time in adults: a systematic review and meta-analysis of controlled trials. Obes Rev. 2014; 15(11): 905-919.

PubMed Abstract | Publisher Full Text | Free Full Text

Philis-Tsimikas A, Walker C, Rivard L, et al.: Improvement in diabetes care 
of underinsured patients enrolled in project dulce: a community-based, culturally appropriate, nurse case management and peer education diabetes care model. Diabetes Care. 2004; 27(1): 110-5. PubMed Abstract | Publisher Full Text

Ramachandran A, Snehalatha C, Kapur A, et al:: High prevalence of diabetes and impaired glucose tolerance in India: National Urban Diabetes Survey. Diabetologia. 2001; 44(9): 1094-101.

PubMed Abstract | Publisher Full Text

Ries AV, Blackman LT, Page RA, et al.: Goal setting for health behavior change: evidence from an obesity intervention for rural low-income women. Rural Remote Health. 2014; 14: 2682.

PubMed Abstract

Rodondi N, Humair JP, Ghali WA, et al.: Counselling overweight and obese patients in primary care: a prospective cohort study. Eur J Cardiovasc Prev Rehabil. 2006; 13(2): 222-8.

PubMed Abstract | Publisher Full Text

Roux L, Pratt M, Tengs TO, et al.: Cost effectiveness of community-based physical activity interventions. Am J Prev Med. 2008; 35(6): 578-88. PubMed Abstract | Publisher Full Text

Samitz G, Egger M, Zwahlen M: Domains of physical activity and all-cause mortality: systematic review and dose-response meta-analysis of cohor studies. Int J Epidemiol. 2011; 40(5): 1382-400.

PubMed Abstract | Publisher Full Text

Satish T: Change in Cardiovascular Risk Factor Profile of a Rural Cohort in Thiruvananthapuram District in Kerala. Unpublished master's thesis. Achutha Menon Centre for Health Science Studies (AMCHSS), Trivandrum, India. 2008.

Reference Source

Sathish T, Williams ED, Pasricha $N$, et al: Cluster randomised controlled trial of a peer-led lifestyle intervention program: study protocol for the Kerala Diabetes Prevention Program. BMC Public Health. 2013; 13: 1035.

PubMed Abstract | Publisher Full Text | Free Full Text

Sauzet $\mathrm{O}$, Kleine $\mathrm{M}$, Menzel-Begemann $\mathrm{A}$, et al.: Longitudinal randomised controlled trials in rehabilitation post-stroke: a systematic review on the quality of reporting and use of baseline outcome values. BMC Neurol. 2015;
15: 99

PubMed Abstract | Publisher Full Text | Free Full Text

Shah B, Mathur P: Surveillance of cardiovascular disease risk factors in India: the need \& scope. Indian J Med Res. 2010; 132(5): 634-42.

PubMed Abstract | Publisher Full Text | Free Full Text

Smith PG, Morrow RH: (Eds.). Field trials of health interventions in

Developing countries: A tool box. London: Macmillan Education limited. 1996. Reference Source

Silva DAS, Tremblay MS, Marinho F, et al.: Physical inactivity as a risk factor for all-cause mortality in Brazil (1990-2017). Popul Health Metr. 2020; 18(Suppl 1): 13.

PubMed Abstract | Publisher Full Text | Free Full Text

Stephens T, Jacobs DR, White CC: A descriptive epidemiology of leisure-time physical activity. Public Health Rep. 1985; 100(2): 147-58.

PubMed Abstract | Free Full Text

Thankappan KR, Shah B, Mathur P, et al.: Risk Factor Profile for Chronic NonCommunicable Diseases: Results of a Community-Based Study in Kerala, India. Indian I Med Res. 2010; 131: 53-63.

PubMed Abstract

Wattanapisit A, Tuangratananon T, Thanamee S: Physical activity counseling in primary care and family medicine residency training: a systematic review. BMC Med Educ. 2018; 18(1): 159.

PubMed Abstract | Publisher Full Text | Free Full Text

World Health Organization: WHO STEPS surveillance manual. The WHO STEP wise approach to chronic disease risk factor surveillance. Geneva, 2005; Retrieved August 8, 2011.

Reference Source

World Health Organization: (n. d). Guidelines for Data Processing and Analysis of the Global Physical Activity Questionnaire (GPAQ). Retrieved June 27, 2013.

Reference Source

World Health Organisation: Global Strategy on Diet, Physical Activity and Health. 2004; Retrieved February 19, 2021.

Reference Source 


\section{Open Peer Review}

\section{Current Peer Review Status:}

\section{Version 1}

Reviewer Report 01 June 2021

https://doi.org/10.21956/wellcomeopenres.18321.r43732

(C) 2021 Sreedevi A. This is an open access peer review report distributed under the terms of the Creative Commons Attribution License, which permits unrestricted use, distribution, and reproduction in any medium, provided the original work is properly cited.

\section{Aswathy Sreedevi}

Department of Community Medicine, Amrita Institute of Medical Sciences, Kochi, Kerala, India

The paper by Elezebeth Mathews et al. is a well written document of the outcomes of an intervention on improving physical activity which has been diligently executed. Current literature has been cited appropriately. The study design is appropriate. Sufficient details of the methods are provided. The statistical analysis is appropriate.

- The intervention consisted of a NCD risk assessment, educational workshop, group counselling sessions and goal setting. The authors report a significant improvement in physical activity in the intervention arm at 4th and 13th month. It is a complex intervention at multiple levels.

The intervention was delivered at the cluster level and the outcomes are measured at the individual level which can lead to some bias, though it may be minimal due to a similar demographic distribution of the women. Did the sedentary only attend the NCD risk assessment camp?

The timeline for the conduct of the study does not take into account the duration of the baseline, midline and endline surveys.

Any particular reason why the response is greater in the second wave of screening? The drop out rate is next to negligible in both the arms. It would also be interesting for the readers to know if there is any particular reason for this.

In intervention development, "Lack of knowledge/awareness on physical activity recommendations, benefits of PA, activities to engage...were key findings..." can the authors be more specific on this?

It would be good if tables 3 and 4 are simplified and repetition avoided. For example, Table 4 could be written as: 


$\begin{array}{ccccccccc} & 0 & 4 & 7 & 13 \text { months } & 0 & 4 & 7 & 13 \text { months } \\ \text { BMI } & 26.96 & 26.85 & 27.79 & 26.72 & 26.85 & - & 27.09\end{array}$

Table 5 mentions the coefficient of change - what is presented in the table seems to be absolute difference in met minutes/week from baseline to $4^{\text {th }}$ month, baseline to $7^{\text {th }}$ month etc.

Are there any unintended effects of the intervention? This should also be mentioned.

In the abstract, in conclusion it is mentioned that physical activity can be integrated with community organisations - this is not very clear.

The multiple levels of intervention make it difficult to assess which intervention is the most effective and can be a limitation too.

I would recommend this paper for acceptance as it is a logical and cohesive piece of work carried out scientifically to improve physical activity.

Is the work clearly and accurately presented and does it cite the current literature? Yes

Is the study design appropriate and is the work technically sound? Yes

Are sufficient details of methods and analysis provided to allow replication by others? Yes

If applicable, is the statistical analysis and its interpretation appropriate? Yes

Are all the source data underlying the results available to ensure full reproducibility? Yes

Are the conclusions drawn adequately supported by the results? Yes

Competing Interests: No competing interests were disclosed.

Reviewer Expertise: Non Communicable Disease and Cancer screening

I confirm that I have read this submission and believe that I have an appropriate level of expertise to confirm that it is of an acceptable scientific standard.

Reviewer Report 24 May 2021

https://doi.org/10.21956/wellcomeopenres.18321.r43731 
(C) 2021 Mithra P. This is an open access peer review report distributed under the terms of the Creative Commons Attribution License, which permits unrestricted use, distribution, and reproduction in any medium, provided the original work is properly cited.

\section{P. Prasanna Mithra}

Kasturba Medical College Mangalore, Manipal Academy of Higher Education, Manipal, Karnataka, India

This non-randomized quasi experimental study has a strong literature back up. Methods have been spelled out adequately and there is clear explanation of execution of the interventions across two arms.

Plus point of this study is considering the natural living conditions of study participants and making these interventions "culture friendly". This would enhance the acceptability of these interventions in real world situations in future.

One challenge in generalizing the findings would be in the relatively different age group proportions in the two arms. The intervention arm seems to have slightly higher proportion of women in younger age groups. The age factor has a lot of role to play in mobility status of women.

Also, it would add value to the description; if an account of 2 wave screening is given (the reason and circumstances for carrying out screening in 2 waves).

Is the sampling strategy followed the same as given in Mathews $2015 ?$

Is the work clearly and accurately presented and does it cite the current literature? Yes

Is the study design appropriate and is the work technically sound?

Yes

Are sufficient details of methods and analysis provided to allow replication by others? Partly

If applicable, is the statistical analysis and its interpretation appropriate? Yes

Are all the source data underlying the results available to ensure full reproducibility? Yes

Are the conclusions drawn adequately supported by the results? Yes

Competing Interests: No competing interests were disclosed. 
Reviewer Expertise: Non Communicable Diseases (NCD), Nutrition

\section{I confirm that I have read this submission and believe that I have an appropriate level of expertise to confirm that it is of an acceptable scientific standard.}

Reviewer Report 17 May 2021

https://doi.org/10.21956/wellcomeopenres.18321.r43733

(C) 2021 Varma R. This is an open access peer review report distributed under the terms of the Creative Commons Attribution License, which permits unrestricted use, distribution, and reproduction in any medium, provided the original work is properly cited.

\section{Ravi Prasad Varma}

Achutha Menon Centre for Health Science Studies, Sree Chitra Tirunal Institute for Medical Sciences and Technology, Thiruvananthapuram, Kerala, India

The paper by Mathews E et al. describes the attempt by the investigators to increase the proportion of women in the intervention area in Thiruvananthapuram city who were physically active. Intervention and control areas were identified a priori. Women included in the study were identified to be sedentary through a screening survey which had two phases. A validated version of the Global Physical Activity Questionnaire (GPAQ) was used to measure physical activity - the outcome of interest. Metabolic equivalent task (MET) minutes per week levels were used to categorize participants into sedentary, moderate, or high levels of physical activity. The intervention is somewhat complex, with an amalgamation of community-level activities, group sessions, and peer-leader-led activities. Culturally appropriate forms of physical activity were identified and included in the study materials and interventions. The investigators conclude the intervention was effective in improving physical activity levels in women.

Pertinent literature relevant to the research question has been reviewed rather well. The study design and participant selection are clearly described and appropriate. The intervention and control groups are comparable and the statistical analysis is suitable for the hypotheses tested and the conclusion drawn. Given the non-individual nature of the intervention, the groups formed per se may affect the intervention. That looks unlikely in this study as, in addition to similar physical activity levels at baseline (all were sedentary) there was a good chance of forming groups that were of similar demographics and living contexts. Given the gendered nature of the community, women's access and roles in outdoor spaces could come under scrutiny from their families and the community. In this regard, the investigators' efforts for community engagement and efforts for community ownership are very commendable and constitute good public health research practice.

Envisioning process indicators based on the individual components of the interventions is tough in such a study and the investigators seem to have remained pragmatic in their approach. However, it is not clear how the investigators have conceptualized the dose-response relationship in this study. Interventions were tapered and physical activity decreased - whether that amounts to a dose-response relationship is questionable. I would recommend some caution while making 
statements suggesting implementation strength. Moreover, while it looks beyond the scope of this manuscript, I suggest exploring more clear-cut approaches to intervention strength if possible (Hargreaves et al. 2016¹).

The discussion portion has some other limitations too - the discussion on the possibility of measurement bias is mentioned but limited. There is also no mention of - (1) the physiological variables; (2) safety of the intervention/ possibility of harm - in the discussion. The lack of change in body mass index and waist circumference in physical activity interventions has been reported earlier and can be mentioned (Lamb et al. 2002²).

I also suggest a few other minor edits/ corrections. The figure 1 legend may indicate that 'I' stands for intervention arm and ' $C$ ' for the control arm. Also, it may be indicated that the injury in the intervention group was independent of the intervention, if it were so. There are also a few minor typos - e.g. under the section "intense phase of intervention", I think the authors meant NCDs in place of NCDSs.

The main contribution of the paper is that there is very little published scientific literature on health promotion among women in low-and middle-income countries where women's health is rarely envisaged beyond maternal health. Therefore I strongly recommend that this paper be accepted with minor revisions.

\section{References}

1. Hargreaves JR, Goodman C, Davey C, Willey BA, et al.: Measuring implementation strength: lessons from the evaluation of public health strategies in low- and middle-income settings. Health Policy Plan. 2016; 31 (7): 860-7 PubMed Abstract | Publisher Full Text

2. Lamb SE, Bartlett HP, Ashley A, Bird W: Can lay-led walking programmes increase physical activity in middle aged adults? A randomised controlled trial.J Epidemiol Community Health. 2002; 56 (4): 246-52 PubMed Abstract | Publisher Full Text

Is the work clearly and accurately presented and does it cite the current literature? Yes

Is the study design appropriate and is the work technically sound?

Yes

Are sufficient details of methods and analysis provided to allow replication by others? Yes

If applicable, is the statistical analysis and its interpretation appropriate? Yes

Are all the source data underlying the results available to ensure full reproducibility? Yes

Are the conclusions drawn adequately supported by the results? Yes 
Competing Interests: No competing interests were disclosed.

Reviewer Expertise: Epidemiology, Health care systems

I confirm that I have read this submission and believe that I have an appropriate level of expertise to confirm that it is of an acceptable scientific standard. 